*Artigo resultante de trabalho de conclusão de curso apresentado ao Programa de Pós-graduação na modalidade Residência Multiprofissional em Saúde da Família da Faculdade de Medicina de Botucatu - Universidade Estadual Paulista (Unesp).

1 Universidade Estadual Paulista (Unesp) -

Botucatu, São Paulo, Brasil. suelenalvesrocha@gmail.com

2 Universidade Estadual Paulista (Unesp) -

Botucatu, São Paulo, Brasil. rstella@fmb.unesp.br

\title{
Acolhimento na visão complexa: ação coletiva emergente na Equipe de Saúde da Família $^{\star}$
}

User embracement in complex vision: collective action emerging in
the Family Health Team

Suelen Alves Rocha1, Regina Stella Spagnuolo²
RESUMO Pesquisa qualitativa que objetivou compreender a experiência da equipe com a prática do acolhimento na Estratégia Saúde da Família. O grupo focal conduzido com 13 integrantes da equipe, a análise de conteúdo sistematizou os dados. A Teoria da Complexidade e acolhimento-diálogo compuseram o referencial teórico. A equipe que atua como Sistema Dinâmico Complexo e Adaptativo pode ter o acolhimento como qualidade emergente. O potencializar das relações-encontros possibilita respostas diferentes aos modos de ser e agir do modelo newtoniano-mecanicista.

PALVRAS-CHAVE Estratégia Saúde da Família; Acolhimento; Atenção Primária à Saúde; Dinâmica não linear.

ABSTRACT This qualitative research aimed to understand the team's experience with the practice of user embracement in the Family Health Strategy. The focus group conducted with 13 members of staff, content analysis systematized data. The Complexity Theory and user embracement dialogue comprised the theoretical framework. The team that acts as Complex and Adaptive Dynamics system can have the user embracement as an emerging quality. The potentiation of relations-meetings to enable different responses to the modes of being and acting of the Newtonian mechanistic model answers.

KEYWORDS Family Health Strategy; User embracement; Primary Health Care; Nonlinear dynamics. 


\section{Introdução}

A crise estrutural do subsetor público de saúde brasileiro evidenciada na década de 1990, decorrente dos problemas de acesso, humanização e resolubilidade dos serviços, impulsionou algumas proposições alternativas: modelo de vigilância em saúde (sousA; HAMANN, 2009), estabelecimento de ações programáticas, acolhimento, vínculo, entre outras (VIEIRA-DA-SILVA ET AL., 2010).

Diversas experiências concretas foram operacionalizadas a partir desse período visando à superação dos problemas elencados. Assim, o acolhimento adquiriu espaço importante no cenário nacional como dispositivo indutor de modificações organizacionais, como a melhoria do acesso, do trabalho em equipe e da relação técnico-usuário (MITRE; ANDRADE; COTTA, 2012).

Pesquisas posteriores demonstraram que o acolhimento possibilitou o estabelecimento de espaços de conversação entre profissionais e usuários (OLIVEIRA ET AL., 2008; ASSUNÇÃO; URSINE, 2008); estímulo ao autocuidado (ASSUNC̦ÃO; URSINE, 2008); maior visibilidade ao trabalho dos profissionais não médicos; melhoria de acesso; atenção mais qualificada e humanizada (OLIVEIRA; TUNIN; SILVA, 2008); práticas inovadoras, como acolhimento coletivo (CAVALCANTE FILHO ET AL., 2009) e de segmentos marginalizados da sociedade (ABDALLA; NICHIATA, 2008; ROMANO, 2008).

Contudo, outros estudos apontam que problemas com o acesso avançado ainda são abordados tangencialmente (VIEIRA-DA-SILVA ET AL., 2010); a incorporação do acolhimento como ferramenta parcelar no processo de trabalho acarreta prejuízo na resolubilidade dos serviços (SCHOLZE, 2009) e sofrimento ao trabalhador (MITRE; ANDRADE; COTTA, 2012; SCHOLZE, 2009); a gestão coparticipativa do cuidado é pouco discutida na literatura nacional (MITRE; ANDRADE; COTTA, 2012); a qualificação da relação usuário-profissional e ampliação do reconhecimento das necessidades de saúde solicitam mudanças organizacionais (FALK ET
AL., 2010) e nas bases de estruturas mentais que definem o cuidado (MITRE ET AL., 2012; CAVALCANTE ET AL., 2009) as mudanças organizacionais adotadas pelos serviços fundamentam-se no controle dos usuários (MITRE; ANDRADE; COTTA, 2012); fragilidades no processo de educação permanente (MITRE; ANDRADE; COTTA 2012); profissionais com formação que privilegia ações curativas, fragmentadas, mecanizadas e médico-centradas (OLIVEIRA; TUNIN; SILVA, 2008; FREIRE ET AL., 2008). Esses achados apontam desafios na incorporação do acolhimento, sugerindo, em última instância, uma mudança paradigmática.

O paradigma hegemônico na saúde (mecanicista-newtoniano) originou o modelo biomédico, caracterizado pela separação corpo-mente, saúde-doença, parte-todo. Tal abordagem fortalece um modelo assistencial centrado no hospital, dependente de especialidades médicas, que valoriza o uso de tecnologias pesadas, resultando em elevados custos econômicos com pouco impacto na produção de saúde e formação humanística (BRASIL, 2010).

Segundo Morin (2008), essa realidade fragmentada-reduzida solicita a adoção de um princípio organizador e explicativo, denominado princípio da complexidade:

É certo que ele [princípio da complexidade] se baseia na necessidade de distinguir e de analisar, como o precedente, mas, além disso, procura estabelecer a comunicação entre aquilo que é distinguido: o objeto e o ambiente, a coisa observada e o seu observador. Esforça-se não por sacrificar o todo à parte, a parte ao todo, mas por conceber a difícil problemática da organização. [...] Esforça-se por obter a visão poliocular ou polioscópica, em que, por exemplo, as dimensões físicas, biológicas, espirituais, culturais, sociológicas, históricas daquilo que é humano deixem de ser incomunicáveis. (MORIN, 2008, P. 30).

Neste artigo, a Equipe de Saúde da Família (EqSF) foi concebida como Sistema 
Dinâmico Complexo e Adaptativo (SDCA) que, segundo Kirsbaum (2002), incorpora a não linearidade, a imprevisibilidade, o dinamismo da relação entre as partes, alta sensibilidade às condições iniciais e capacidade de auto-organização. Adicionalmente, apresentar-se-á a Teoria da Complexidade aliada ao acolhimento-diálogo, lançando nova luz à prática do acolhimento, que pode ser compreendido como um fenômeno emergente.

Mediante o exposto, questiona-se: A EqSF organiza-se como um SDCA tendo o acolhimento como qualidade emergente? Para tanto, objetivou-se compreender a experiência da equipe com a prática do acolhimento na Estratégia Saúde da Família (ESF).

\section{Método}

Estudo de abordagem qualitativa realizado em uma Unidade de Saúde da Família (USF) de um município do interior paulista. No início de 2012, a população cadastrada na USF era de 951 famílias, totalizando 3.747 pessoas.

Essa USF, após dez anos de sua implantação (2003-2013), foi selecionada pelo gestor municipal para implementação do projeto de qualificação do processo de trabalho e produção do cuidado em Atenção Primária à Saúde (APS) e constitui um dos espaços de desenvolvimento do Programa de Residência Multiprofissional em Saúde da Família, desenvolvimento de projetos do Programa de Educação para o Trabalho (PET) e da disciplina da graduação Interação Universidade, Serviço e Comunidade (Iusc) que integra os cursos de enfermagem, nutrição e medicina nos três primeiros anos.

Os dados foram coletados em maio de 2012 por meio da técnica de grupo focal, com a presença de um moderador e dois observadores. Em geral, o grupo focal é utilizado para estudar as diferentes opiniões, atitudes e percepções sobre um tema, um fato ou prática que emergem na interação grupal, possibilitando a construção de um conhecimento coletivo (VICTORIA; KNAUTH; HANSSEN, 2000). O encontro teve duração média de uma hora e foi norteado pelas questões: 1. Conte-me, para você o que é o acolhimento? 2. Como o acolhimento acontece na rotina diária de trabalho da EqSF? 3. Quais desafios são enfrentados para incorporação do acolhimento na prática?

Assim, o grupo focal foi composto por 13 profissionais, sendo: um enfermeiro, um médico, um dentista, um residente multiprofissional dentista, um residente multiprofissional fisioterapeuta, dois auxiliares de enfermagem, um auxiliar em saúde bucal, três agentes comunitários de saúde, um auxiliar de serviços gerais e um auxiliar administrativo, de maneira a obter representação de todos os membros da equipe multiprofissional. A participação dos profissionais no encontro transcorreu com tranquilidade, respeitando-se a técnica do grupo focal.

Os discursos foram gravados por meio digital, transcritos na íntegra e posteriormente eliminadas as gravações. A coleta de dados foi realizada após aprovação no Comitê de Ética em Pesquisa local, conforme ofício $\mathrm{n}^{0} 23 / 2012$, e a confirmação de participação dos profissionais por meio da assinatura do Termo de Consentimento Livre e Esclarecido, conforme Resolução ${ }^{\circ}$ 466/2012 do Conselho Nacional de Saúde.

Para tratamento dos dados, utilizou-se a análise de conteúdo na abordagem representacional temática proposta por Bardin (2009), alicerçada nas fases: pré-análise, análise e exploração do material.

Como referenciais teóricos para alicerçar a discussão das categorias temáticas, utilizou-se o acolhimento-diálogo, conceito proposto por Teixeira (2005A, 2005B, 2003), e a Teoria da Complexidade a partir de conceitos de Wheathey (2004) e Mariotti (2010).

O acolhimento-diálogo proposto por Teixeira (2005A, 2003) é um dispositivo indispensável para o bom desempenho da lógica 
tecnoassistencial. Teixeira aborda-o em uma perspectiva essencialmente 'comunicacional', entendendo a rede tecnoassistencial de um serviço de saúde como uma rede de conversações - cada nó dessa rede corresponde a um encontro, um momento de conversa envolvendo uma série de atividades técnicas específicas.

Por outro lado, as ciências da complexidade surgiram no século XX compreendendo um conjunto de disciplinas cuja finalidade é estudar os fenômenos complexos, permitindo a extração de princípios bem fundamentados. Entre as escolas que as compõem, destaca-se a teoria do caos, a matemática dos fractais, a teoria de estruturas dissipativas, de Ilya Prigogine, e a escola de Edgar Morin. Tais aplicações se estendem a quase todas as áreas da atividade humana, entre elas a educação, as ações em saúde, o mundo dos negócios, economia e administração. A complexidade tem sido entendida como o tecido de acontecimentos, ações, interações, retroações, determinações, acasos que constituem o nosso mundo fenomenal (MORIN, 1990).

\section{Resultados e discussão}

A partir das questões norteadoras aplicadas ao grupo focal, desvelaram-se quatro categorias temáticas que elucidam a prática do acolhimento na realidade dinâmica de trabalho na EqSF. Essas categorias se articulam de forma complementar permitindo a compreensão em profundidade dos cenários e razões que dificultam a emergência do acolhimento.

- Estabelecendo a empatia e a verticalidade das relações no cuidar: contradições do acolher. Apresenta o modelo assistencial biomédico dificultando que profissionais da equipe de saúde ultrapassem o simples estabelecimento de um encontro empático com usuários em direção à alteridade inerente ao acolhimento.
- Vivenciando a multiplicidade do acolher e os enfrentamentos para sua realização. Discute o acolhimento como ação coletiva emergente de uma equipe que atua em condições organizativas, estruturais e relacionais que permitem sua aproximação do conceito de SDCA.

- Triar ou acolher: interfaces do trabalho na EqSF. Enquanto SDCA, a EqSF tem potencial para auto-organização (tendo o acolhimento como qualidade emergente) ao perceber os ruídos e responder de maneira inovadora às pressões do meio ambiente, desde que seus membros possuam autonomia e diretrizes de autorreferência organizacional.

- Desafios na incorporação do acolhimento no cotidiano laboral. A incorporação do acolhimento solicita um modelo assistencial alternativo que qualifique as relações, promova a coparticipação na gestão do serviço e permita a atuação multiprofissional. Apontase a necessidade de líderes com visão complexa que saibam lidar com as incertezas e contradições do trabalho em saúde.

\section{Estabelecendo a empatia e a verticalidade das relações no cuidar: contradições do acolher}

A partir dos discursos, evidenciou-se o comportamento empático dos membros da equipe. Há o entendimento de que o acolhimento estabelece um encontro entre profissional e usuário possibilitando o exercício da capacidade de perceber a subjetividade do outro. Esse encontro permite uma suposição bastante acertada dos sentimentos do usuário, a compreensão das necessidades que o levaram à unidade de saúde e, consequentemente, a busca de possibilidades de respostas às problemáticas elencadas. 
Então, receber aquela pessoa, ver o que ela precisa, sentir a necessidade dela, como se fosse um atendimento mais humanizado. Seria ouvir esta pessoa e tentar, no caso, ser resolutiva. (P6.1).

No entanto, a contradição emerge no momento em que são reproduzidas práticas de relações verticais fundamentadas na comunicação linear - 'emissor' e 'receptor' - que remetem à afirmação das relações de poder tão comuns no processo cuidar.

Nesta parte do acolhimento, você tem que impor sua opinião profissional, tem que falar: - Você tem a sua opinião como pessoa, como cidadão, fique à vontade, mas às vezes a sua opinião não condiz com o que é a realidade do tratamento. [...] você (profissional) tem que pegar e mostrar (ao usuário) qual é o lugar dele! Não é muito legal essa expressão. (P7.11).

Nesse contexto, apresenta-se o acolhimento-diálogo como uma resposta possível aos problemas de vínculo e acolhimento que comumente acontecem nos serviços de saúde. Trata-se de uma técnica de conversa que pode ter lugar em qualquer atendimento e/ou encontro com os usuários (TEIXEIRA, 2003). Busca a maior compreensão das necessidades do outro, obedecendo algumas disposições ético-cognitivas: todos sabem algo, ninguém sabe tudo e a conversa não torna os sentidos homogêneos ao diluir as divergências, mas faz emergir o sentido a partir delas (TEIXEIRA, 2005A).

Teixeira (2005A) esclarece que nesses encontros os afetos são criados e manipulados (afetabilidade). O primeiro impacto afetivo é efetivo quando mobiliza afetos que conduzem ao estabelecimento do vínculo, podendo ser comparado a uma relação de empatia. Ao ultrapassar a empatia e estabelecer uma 'zona de comunidade' (reconhecimento do que convém no encontro), chega-se ao segundo impacto, onde afetos de confiança podem ser alcançados.
Quando a confiança é estabelecida, os sujeitos têm a liberdade de mostrar sua singularidade, passando do afeto de confiança (que sustenta o vínculo) ao afeto de acolhimento (terceiro impacto afetivo), onde começa o desafio da alteridade (TEIXEIRA, 2005A).

Segundo Scholze, Duarte Junior e Flores e Silva (2009), o conceito de alteridade, oriundo da antropologia, nega a existência de um centro do mundo ou do saber e aceita a pluralidade da humanidade e de culturas (com suas próprias complexidades e maturidade). Não se trata apenas da observação de diferentes realidades culturais, mas de admitir outro ponto de vista, por meio da experimentação da realidade cultural alheia, reconhecendo o outro como sujeito relacional em sua singularidade e não apenas como objeto.

Dessa forma, a empatia do profissional permite a compreensão dos afetos alheios, enquanto a alteridade aceita o outro como sujeito em seu sofrimento, ao invés de deter-se na doença, ampliando a capacidade de enfrentamento das situações problemas compartilhadas nos serviços de saúde (SCHOLZE; DUARTE JUNIOR; FLORES E SILVA, 2009).

Teixeira (2003) revela a necessidade de superação do 'monopólio do diagnóstico de necessidades' e da integração da 'voz do outro'. Considera ainda que a superação da 'cisão eu-outro' - mais uma modalidade de fragmentação em saúde - favoreceria uma intervenção para além da doença ou do corpo doente.

Entende-se que a concepção newtoniano-mecanicista em saúde, inerente ao modelo assistencial hegemônico, valoriza a formação clínica e de subespecialidades, e subestima o aspecto subjetivo/relacional do encontro com O usuário (MORETTI-PIRES, 2009). Em adição, a supervalorização do conhecimento acadêmico resulta na supremacia/dominação do poder do profissional sobre a saúde do usuário, enfatizando a dimensão biológica e distanciando-se das dimensões sociais, psicológicas e comportamentais implicadas no processo saúde-doença (MORETTI-PIRES, 2009). Contudo, 
tentar excluir a subjetividade das interações sociais equivale a tentar extinguir a humanidade dos seres humanos (MARIOTTI, 2010).

Portanto, atuar na lógica do modelo assistencial biomédico, apesar das tentativas de modificá-la, confere a permanência da contradição entre o discurso (ideal almejado) e o estado atual das práticas em saúde. Logo, o simples exercício da empatia não é suficiente para consolidação do acolhimento.

\section{Vivenciando a multiplicidade do aco- Iher e os enfrentamentos para sua realização}

Os discursos revelaram a multiplicidade do acolher em diferentes espaços no seu cotidiano laboral, tais como: discussão de casos, escuta qualificada, observação da comunicação não verbal, abordagem domiciliar e empoderamento do usuário. Observou-se, ainda, não existir um lugar destinado ao acolhimento. Acontece em todos os espaços possíveis, dentro ou fora da unidade de saúde. "[...] às vezes um bom dia, já vejo um profissional com outro discutindo o caso, as auxiliares saem atrás pra saber qual é o problema, tem andado" (P11.4).

Entretanto, emergiram dos discursos limitações em relação ao ato de acolher atribuídas aos próprios membros da equipe, ao usuário e à gestão do processo de trabalho: a falta de comunicação entre os profissionais, o imediatismo e individualismo dos usuários, a demanda espontânea crescente, a burocracia e a limitação do tempo.

[...] eu acredito que às vezes não é do jeito que deveria ser. Cada profissional tem a sua particularidade, tem alguns que [...] conseguem dar uma escuta mais qualificada, outros não gostam muito, já percebo um pouco de barreira. (P6.6).

Mas se tivesse um espaço que tivesse mais auxiliares, que ela (auxiliar de enfermagem) não tivesse que entrar no sistema pra dar baixa em tudo, se não tivesse uma fila na farmácia, provavelmente esse acolhimento que já existe seria melhor [...]. É muita diferença. Há oito anos, eu tinha cento e trinta famílias, hoje eu estou com duzentos e oito famílias e mais algumas que já pediram cadastro. (P1.14).

Nesse contexto, o acolhimento-diálogo pode funcionar como um operador presente em todos os pontos da rede de serviços (encontros com os usuários). O bom funcionamento desta rede depende do desempenho da recepção do usuário (processo de investigação, elaboração e negociação de suas necessidades), atividade não circunscrita a determinados espaços formais. Quanto maior a plasticidade dessa rede, maior a quantidade de singularizações possíveis. Assim, a possibilidade de diferentes indivíduos realizarem diferentes usos assistenciais pressupõe maior adaptabilidade do sistema à diversidade de necessidades (TEIXEIRA, 2003).

Concernente à relação da ação coletiva e individual, nada garante que todos os membros da equipe agirão para atingir determinado objetivo, ainda que todos fossem beneficiados. No entanto, a adesão do profissional não depende apenas das preferências pessoais. Antes, requer uma negociação na dinâmica do coletivo no qual está inserido (TEIXEIRA, 2005B). Portanto, os gestores (municipal e local) têm importante papel como mediadores da interação social, podendo promover (ou não) valores de integração e confiança entre indivíduos e grupos. Assim, Teixeira (2005B) considera necessário investimento no capital social visando ampliar a potência das ações coletivas.

Capital social é a capacidade de uma sociedade constituir laços de confiança interpessoal e redes de cooperação objetivando a produção de bens comuns (D'ARAúJo, 2003). Desse modo, a confiança e qualidade dos laços sociais (capital social) interferem na construção coletiva do acolhimento e seus desdobramentos possíveis. Contudo, a ação coletiva na EqSF não depende apenas das 
formas concretas de organização do trabalho, mas também da distribuição de poder na equipe. De acordo com Teixeira (2005A), a contradição entre o interesse individual e coletivo só tem lugar quando o homem está impedido de realizar plenamente seu direito natural (seu desejo/potência 'de governar e não ser governado'), isto é, quando há uma relação opressora.

Para Mariotti (2010), tudo que dificulta a autonomia e liberdade das pessoas pode ser considerado violência, incluindo as tentativas de condicionamento e determinação da forma de resposta das pessoas às pressões adaptativas do meio ambiente.

Nesse cenário, ao considerar que os grupos, organizações e instituições humanas são exemplos de SDCA, entende-se que o conhecimento desses sistemas pode auxiliar no processo de mudança comportamental dos membros da equipe, impulsionando a ressignificação das práticas e, em uma lógica de circularidade, incrementando qualitativamente as relações interpessoais e a produção coletiva do cuidado. Os SDCA são sistemas complexos caracterizados por baixa precisão e repetitividade, e, simultaneamente, grande adaptabilidade, criatividade e capacidade de inovar, além de possuírem um nível de erro mais elevado e incerteza (MARIOTTI, 2010).

Segundo Mariotti (2010), o contexto complexo é o domínio das múltiplas possibilidades. Logo, as práticas bem delimitadas e explicadas (melhores práticas) não atingem os resultados esperados. Quando isso acontece, culpabilizam-se as práticas, o modo de empregá-las ou as pessoas que as usam. Torna-se hábito trocar práticas e pessoas, somente para constatar que isso raramente resolve, quando, na verdade, esse cenário sinaliza a necessidade de práticas emergentes e adaptativas, implicadas em uma nova visão desse processo.

As instituições de saúde, entendidas como SDCA, têm capacidade interior para criar estruturas adequadas ao momento (adaptar-se), desde que seja permitido que a tarefa determine a forma organizacional (direcionamento coerente) e que as estruturas rígidas sejam substituídas pela capacidade de agir com flexibilidade às mudanças internas e externas.

Uma organização só evolui, nesse sentido, quando tem acesso às informações relativas a fatores externos e recursos internos, possibilitando o incremento da capacidade de autopercepção, incorporando uma multiplicidade de mecanismos de avaliação e uma vigorosa capacidade de reflexão. A receptividade às informações ambientais ao longo do tempo propicia um sentido mais forte de identidade, tornado a organização menos permeável às mudanças induzidas pelo ambiente externo, em uma dinâmica auto-organizadora do sistema (WHEATLEY, 2004).

O conceito de auto-organização refere-se à habilidade de reconfiguração organizacional do sistema para lidar com novas informações. Níveis crescentes de perturbação no sistema impulsionam a autorrenovação, ultrapassando a simples estabilidade (WHEATLEY, 2004).

Em suma, um modelo de gestão participativo que permita espaços de construção coletiva compartilhando poder - por meio da participação na tomada de decisões e incremento das informações circuladas numa lógica de retroalimentação do sistema parece ser uma alternativa para a implementação do acolhimento em serviços de saúde.

\section{Triar ou acolher: interfaces do traba- Iho na EqSF}

Nessa categoria, surge fortemente a noção de triagem como um ato similar ao acolhimento. Porém, algumas dúvidas sobre competências técnicas e conceitos se apresentam e a equipe discorre a respeito de triagem com classificação de risco e sua interface no acolhimento da USF.

"Mas o que preconiza o Programa de Saúde da Família é que tenha o acolhimento, não que você faça uma triagem, então é uma inversão" (P10.8). 
"A triagem não deixa de atender o paciente, é dar prioridade pra alguém que esteja com uma queixa maior no momento, [...] faz parte do acolhimento saber" (P6.8).

Entende-se por triagem o primeiro atendimento profissional prestado aos usuários do serviço de saúde, objetivando uma avaliação inicial, classificação do risco e encaminhamento adequado às unidades/especialidades de assistência. No Brasil, o termo triagem é pouco aceito, pois historicamente está associado ao ato de dispensar o usuário, sem atendimento (PINHEIRO; OLIVEIRA, 2011).

Dessa forma, para não confundir ou criar resistências, a Política Nacional de Humanização (PNH) propõe o acolhimento com classificação de risco, determinando a agilidade no atendimento a partir da análise, fundamentada em protocolos estabelecidos de forma participativa nos serviços de saúde e avaliação das necessidades do usuário em função do seu risco e vulnerabilidade, garantindo a priorização da atenção e não o atendimento por ordem de chegada. Portanto, realiza-se a análise clínica e ordenação da necessidade, distanciando-se do conceito tradicional de triagem e suas práticas de exclusão, uma vez que todos serão atendidos.

Em resposta aos esforços empreendidos na efetiva organização e estruturação da Rede de Atenção à Saúde (RAS), a Portaria n. ${ }^{0} 4.279$ declara a responsabilidade da APS - como centro comunicacional da RAS - de coordenar e ordenar o cuidado. A Portaria afirma a necessidade de retaguarda adequada pactuada para o referenciamento daqueles pacientes que, uma vez acolhidos, avaliados e tratados nas EqSF necessitem de cuidados disponíveis em serviços de outros níveis de complexidade.

A partir desse entendimento, o acolhimento com avaliação de risco configura-se como uma das intervenções potencialmente decisivas na reorganização e implementação da promoção da saúde em rede, pois em sua concretização ultrapassa o espaço de gestão local apontando, no cotidiano das práticas em saúde, a coexistência das macro e das micropolíticas (BRASIL, 2004).

Sabe-se que estas duas tecnologias - acolhimento e classificação de risco - têm objetivos diferentes, porém complementares, podendo coexistir em espaço físico distinto, mas nunca díspares no processo de trabalho (BRASIL, 2004).

Na USF estudada, o entendimento de acolhimento como uma triagem mais humanizada contribui com a sobrecarga de trabalho, uma vez que corresponde ao ordenamento da demanda espontânea por consulta, em uma concepção médico-centrada privilegiando ações curativas. Dessa maneira, é produzida, na maioria das vezes, uma assistência mecanizada apoiada em protocolos, resultando em prescrições, procedimentos técnicos fragmentados e diminuição da autonomia do usuário. "[...] é muito acolhimento e às vezes atrapalha um pouquinho [...]” (P5.6). "Acolhimento não é simplesmente chegar e ouvir, às vezes precisa dar um puxão de orelha [...] ai a pessoa sintoniza e começa seguir tudo certinho" (P7.11).

Compreende-se que ações de recuperação fazem parte do cuidar, porém devem ser combinadas com outras de promoção e prevenção. Caso contrário, se mantém o ciclo doença-intervenção, diminuição do autocuidado e demanda assistencial crescente e insatisfeita com o serviço.

Nesse contexto, quando um profissional entende que o acolhimento com classificação de risco é mais amplo que triar e incorpora em sua prática outros aspectos relacionais que permitem o encontro com o usuário, acaba por se frustrar ao não obter a retaguarda necessária à demanda levantada. Com o passar do tempo, pode, sem perceber, criar barreiras no acolher por sentir-se impotente, não desejando conhecer algo que não sabe como lidar, vivenciando a dicotomia triar-acolher.

Percebe-se que quando o modelo assistencial não permite a expressão de um dos 
sujeitos aparecem certos ruídos, concebidos inúmeras vezes como desarranjos no processo laboral, sinalizando a necessidade de investimentos em novas formas de gerir e operar o trabalho em saúde. Pinheiro e Oliveira (2011) explicitam o dever de assegurar que o dispositivo do acolhimento atue como diálogo entre os sujeitos, e não como instrumento silenciador de uma condição que requer mudanças.

O ruído organizacional incrementa a complexificação do sistema por lhe permitir aumento de informações e de interconexões disponíveis, ocasionando um maior repertório de possibilidades de respostas às variações ambientais. Portanto, é por meio do ruído organizacional que se pode desenvolver qualidades emergentes mais sofisticadas e eficazes no nível de equipes de trabalho (ALEKSANDROWICZ, 2009).

Wheatley (2004) afirma que os SDCA assinalam a necessidade de respostas inovadoras às perturbações ambientais, que permitam que o sistema se altere de maneira a permanecer coerente com sua própria natureza e ambiente em que se encontra (autorreferência).

Ao se possibilitar autonomia no nível das equipes, deixando pessoas ou unidades dirigirem suas decisões por diretrizes de autorreferência organizacional, pode-se alcançar a coerência e continuidade. A auto-organização é bem sucedida quando oferece sustentação à atividade independente de seus membros ao lhe conceder um forte quadro de referência, permitindo que o sistema alcance maiores níveis de autonomia e integralidade (WHEATLEY, 2004).

Essa autora ressalta que, por vezes, as pessoas apresentam um desejo enraizado de serem governadas, resultando na necessidade de orientação externa, fazendo com que a falta de 'regras claras' (melhores práticas) deixem-nas perdidas. No entanto, esse desejo, quando realizado, tolhe a criatividade e estimula a obediência, o conformismo e a mediocridade. Já as mínimas especificações (direcionamento coerente) estimulam a criatividade e autonomia.

Todavia, na atenção primária, principalmente em USF, o acolhimento tem sido combinado com dispositivos organizacionais tradicionais dos serviços de saúde (recepção, triagem, acesso). Por vezes, sofre uma série de modificações que chega ao limite de esvaziá-lo de significado, sendo apenas um nome novo para uma 'velha' atividade (algum tipo de pronto-atendimento) (TEIXEIRA, 2003).

O conceito de acolhimento não pode ser restrito à recepção da 'demanda espontânea', mas tratado como próprio de um encontro de afetabilidade, como qualificador da relação, passível de ser apreendido e trabalhado em todo e qualquer ponto da rede e não apenas na recepção. $\mathrm{O}$ acolhimento na porta de entrada só tem sentido se entendido como uma passagem para o acolhimento nos processos de produção de saúde (BRASIL, 2004).

\section{Desafios na incorporação do acolhi- mento no cotidiano laboral}

A equipe elenca alguns desafios na incorporação do acolhimento, a saber: imprevisibilidade, imediatismo, individualismo, exigência de produção, fragmentação do ser humano, recursos humanos insuficientes, desconhecimento por parte da comunidade acerca do processo de trabalho na USF e o predomínio do modelo assistencial biomédico.

Pra incorporar o acolhimento como deveria, na teoria é quase impossível, [...] nós lidamos com o ser humano, que tem muitas variáveis. Isso deixa a saúde totalmente imprevisível. (P7.15).

[...] tanto a população, quanto a equipe de saúde estão voltadas para o modelo biomédico, às vezes, tem outras formas de fazer aquela atividade ou de dar conduta pra aquela coisa. (P10.14). 
Pode-se inferir que, no cotidiano de trabalho da USF estudada, o acolhimento aumenta quase que exclusivamente a demanda médica. Este fato foi explicado por Oliveira, Tunin e Silva (2008), mediante algumas proposições: na preferência dos usuários pelo atendimento curativo, influenciados pela cultura de que saúde é ausência de doenças; pela hegemonia histórica médico-curativa que subalterniza a intervenção dos demais profissionais; por ruídos comunicacionais entre usuário e equipe de acolhimento dificultando a verbalização, por parte do usuário, e/ou o entendimento, por parte do profissional, da real necessidade apresentada pelo usuário.

No entanto, segundo Pinheiro e Oliveira (2011), a proposta do acolhimento deveria ser o resgate e o incremento da potência do conhecimento técnico das equipes, permitindo o enriquecimento da intervenção dos vários profissionais da saúde na assistência.

Mais uma vez, apresenta-se a necessidade de mudança no modelo assistencial. Afinal, a pretendida 'reversão do modelo tecnoassistencial' para Teixeira (2003) parece mais ser 'reversão do modelo comunicacional' vigente nos serviços.

Nessa perspectiva, Teixeira (2003) reconhece a importância da transformação da relação profissional-usuário na construção de um modelo assistencial alternativo, capaz de acumular experiências contra-hegemônicas. A possibilidade de ressignificação do usuário no processo de trabalho - em uma dimensão complexa - enfatiza a coparticipação no planejamento da assistência, valorizando os saberes e o entorno sociocultural, num gradativo processo de horizontalização e humanização da relação técnico-usuário (MORETTI-PIRES, 2009).

Todavia, a estratégia metodológica apropriada para elucidar a complexidade dos fenômenos de saúde não se resume a olhares múltiplos, coabitando ou coexistindo em um num determinado campo científico, mas é preciso descobrir a unidade nessa imensa diversidade complexa de objetos, mirantes e olhares (ALMEIDA FILHO, 2005).

Assim sendo, ao deixar o sistema evoluir diante das incertezas e imprevisibilidades inerentes, ver-se-á que a forma dominante das organizações em saúde poderá ser mantida ao se conservar a clareza acerca do propósito e da direção da organização. Ao manter-se o foco, pode-se fazer mais que exercer apenas o controle direto: cria-se a flexibilidade e a responsabilidade pelas quais toda instituição anseia (MARIOTTI, 2010).

Os líderes, em um mundo complexo são convidados a moldar suas organizações por meio de conceitos, em vez de fazê-lo mediante elaboradas regras ou estruturas. A presença desse princípio orientador (autorreferência) permite tanto a criatividade como os limites, tanto a evolução como a coerência, tanto o determinismo como o livre-arbítrio (WHEATLEY, 2004).

\section{Considerações finais}

O uso da técnica de grupo focal, da análise de conteúdo e referenciais teóricos inovadores permitiu compreender e discutir as contradições e aproximações que envolvem a prática do acolhimento na EqSF do ponto de vista da equipe.

A equipe que atua como Sistema Dinâmico Complexo e Adaptativo pode ter o acolhimento como qualidade emergente. Contudo, o contexto na USF apresenta-se ainda fragmentado, mediado pela hierarquização das relações de poder, atravessado por regras rígidas e forte apego ao controle. Tais fatores dificultam a evolução desse sistema, e, por conseguinte, que profissionais ultrapassem o exercício simples da empatia em direção à alteridade inerente ao acolhimento.

É nas relações interpessoais e interprofissionais que está a força para mudanças, a partir da emergência de novos padrões de comportamento que incrementem a criatividade e possibilitem o acolhimento. 
Entende-se que, quando se potencializa essas relações-encontros, abrem-se possibilidades para respostas diferentes aos velhos modos de ser e agir típicos do modelo newtoniano-mecanicista, que dá potência para as tarefas em detrimento das relações.

Assim, as relações gestores, comunidade, profissionais devem ser potencializadas e autorreferenciadas por conceitos claros e inovadores
- fundamentados em um novo paradigma da ciência - que permitam repensar as práticas do acolhimento emergentes nos pontos de encontro da rede tecnoassistencial oferecendo subsídios para evolução desse sistema.

Este artigo, apesar do cenário loco-municipal, oferece evidências explicativas que podem ser aproveitadas em experiências semelhantes.

\section{Referências}

\begin{abstract}
ABDALLA, F. T. M.; NICHIATA, L. Y. I. A abertura da privacidade e o sigilo das informações sobre o HIV/ AIDS das mulheres atendidas pelo programa saúde da família no município de São Paulo, Brasil. Saude soc., São Paulo, v. 17, n. 2, p. 140-52, 2008.
\end{abstract}

ALEKSANDROWICZ, A. M. C. Participação e integração: o ponto de vista das teorias da auto-organização. Cienc. saude colet., Rio de Jnaeiro, v. 14, supl. 1, p. 1609 18, 2009.

ALMEIDA FILHO, N. Transdisciplinaridade e o Paradigma Pós-Disciplinar na Saúde. Saude soc, São Paulo, v. 14, n. 3, p. 30-50, 2005.

ASSUNÇÃO, T. S.; URSINE, P. G. S. Estudo de fatores associados à adesão ao tratamento não farmacológico em portadores de diabetes mellitus assistidos pelo programa saúde da família, Ventosa, Belo Horizonte. Cienc. saude colet., Rio de Janeiro, v. 13, supl. 2, p. 2189 97, 2008.

BARDIN, L. Análise de conteúdo. Lisboa: Edições 70, Lda, 2009

BRASIL. Ministério da Saúde. Conselho Nacional de Saúde. Resolução no 466, de 12 de dezembro de 2012. Institui diretrizes e normas regulamentadoras de pesquisa envolvendo seres humanos. Diário Oficial [da] União, Brasília, DF, 2012. Disponível em: <http:// conselho.saude.gov.br/resolucoes/2012/Reso466.pdf>. Acesso em: 12 abr. 2014.
Ministério da Saúde. Secretaria de Ciência, Tecnologia e Insumos Estratégicos. Como elaborar projetos de pesquisa para o PPSUS: guia. Brasília, DF: Ministério da Saúde, 2010.

Ministério da Saúde. Política Nacional de Humanização (PNH). Relatório Final da Oficina HumanizaSUS. Brasília, DF: Ministério da Saúde, 2004.

Ministério da Saúde. Portaria n. ${ }^{\circ} 4.279$, de 30 de dezembro de 2010. Estabelece diretrizes para a organização da Rede de Atenção à Saúde no âmbito do Sistema Único de Saúde. Diário Oficial [da] União, Brasília, DF, 2010. Disponível em: <http://bvsms.saude. gov.br/bvs/saudelegis/gm/2010/prt4279_30_12_2010. html>. Acesso em: 12 abr. 2014.

CAVALCANTE FILHO, J. B. et al. Acolhimento coletivo: um desafio instituinte de novas formas de produzir o cuidado. Interface (Botucatu), Botucatu, v. 13, n. 31, p. 315-28, 2009.

D’ARAÚJO, M. C. Capital social. Rio de Janeiro: Jorge Zahar, 2003.

FALK, M. L. R. et al. Acolhimento como dispositivo de humanização: percepção do usuário e do trabalhador em saúde. Rev. APS, Juiz de Fora, v. 13, n.1, p. 4-9, 2010.

FREIRE, L. A. M et al. O acolhimento sob a ótica de profissionais da equipe de saúde da família. REME, Belo Horizonte, v. 12, n. 2, p. 271-77, 2008. 
KIRSHBAUM, D. Introduction to Complex Systems Theory: basic definition [internet]. Disponível em: $<$ http://www.calresco.org/intro.htm>. Acesso em: 12 abr. 2014.

\section{MARIOTTI, H. Pensando diferente para lidar com a} complexidade, a incerteza e a ilusão. São Paulo: Atlas S. A., 2010.

MITRE, S. M.; ANDRADE, E. I. G.; COTTA, R. M. M. Avanços e desafios do acolhimento na operacionalização e qualificação do Sistema Único de Saúde na Atenção Primária: um resgate da produção bibliográfica do Brasil. Cienc. saude colet., Rio de Janeiro, v. 17, n. 8, p. 2071-85, 2012.

MORETTI-PIRES, R. O. Complexidade em Saúde da Família e formação do futuro profissional de saúde. Interface (Botucatu), Botucatu, v. 13, n. 30, p. 153-66, 2009.

MORIN, E. Ciência com consciência. 12 ed. Rio de Janeiro: Bertrand Brasil, 2008.

Introdução ao Pensamento Complexo. Lisboa: Instituto Piaget, 1990.

OLIVEIRA, A. et al. A comunicação no contexto do acolhimento em uma unidade de saúde da família de São Carlos, SP. Interface (Botucatu), Botucatu v. 12, n. 27, p. 749-62, 2008.

OLIVEIRA, L. M. L.; TUNIN, A. S. M.; SILVA, F. C. Acolhimento: concepções, implicações no processo de trabalho e na atenção à saúde. Rev. APS, v. 11, n. 4, p. 362-73, 2008.

PINHEIRO, P. M.; OLIVEIRA, L. C. A contribuição do acolhimento e do vínculo na humanização da prática do cirurgião-dentista no Programa Saúde da Família. Interface (Botucatu), Botucatu, v. 15, n. 36, p. 727-39, 2011.

ROMANO, V. F. As travestis no programa saúde da família da Lapa. Saude soc., São Paulo, v. 17, n. 2, p. 211$19,2008$.
SCHOLZE, A. S.; DUARTE JUNIOR, C. F.; FLORES E SILVA, Y. Trabalho em saúde e a implantação do acolhimento na atenção primária à saúde: afeto, empatia ou alteridade? Interface (Botucatu), Botucatu, v. 13, n. 31, p. 303-14, 2009.

SOUSA, M. F.; HAMANN, E. M. Family Health Program in Brazil: an incomplete agenda? Cienc. saude colet., Rio de Janeiro, v. 14, supl. 1, p. 1325-35, 2009.

TEIXEIRA, R. R. Acolhimento num serviço de saúde entendido como uma rede de conversações. In: PINHEIRO, R.; MATTOS, R. A (Org.). Construção da integralidade: cotidiano, saberes e práticas em saúde. Rio de Janeiro: Cepesc, 2003. p. 91-113.

Humanização e Atenção Primária à Saúde. Cienc. saude colet., Rio de Janeiro, v. 10, n. 3, p. 585-97, 2005a.

. O desempenho de um serviço de atenção primária à saúde na perspectiva da inteligência coletiva. Interface (Botucatu), Botucatu, v. 9, n. 17, p. 219-34, $2005 b$.

VICTORA, C.; KNAUTH, D. R.; HANSSEN, M. N. A pesquisa qualitativa em saúde: uma introdução ao tema. Porto Alegre: Tomo Editorial, 2000.

VIEIRA-DA-SILVA, L. M. et al. Avaliação da implantação de programa voltado para melhoria da acessibilidade e humanização do acolhimento aos usuários na rede básica. Salvador, 2005-2008. Rev. Bras. saude mater. infant., Recife, v. 10, supl. 1, p. S131-43, 2010.

WHEATLEY, M. Liderança e a nova ciência. 10 ed. São Paulo: Cultrix, 2004.

Recebido para publicação em julho de 2014

Versão final em dezembro de 2014

Conflito de interesses: inexistente

Suporte financeiro: não houve 